\title{
City dwellers' perception of urban environment in Bhubaneswar, India and its correlates
}

\author{
Nihar Ranjan Rout* a and Ram Babu Bhagat ${ }^{b}$ \\ Built - Environment - Sri Lanka, Vol. 11 , Issue 01 : 2012: 7-13 \\ Key Words - Perception; Urban; Environment; Migrant; Slum; Composite Index
}

\begin{abstract}
This study is an attempt to explore the perception of city dwellers on different aspects of urban environment in the city of Bhubaneswar in India, and analyze its socioeconomic correlates. The survey carried out for the purpose and the composite indices computed afterwards indicated that migrants were less satisfied with the urban environment and services, in comparison to the natives. It was clearly evident that there existed a wide disparity in service provision to slum and non-slum households. As regard the road transport service, the least satisfied were the affluent residents of the good residential area Interestingly, the respondents did not think lack of public transportation facility as a major problem, which could be attributed to the increasing tendency of using personal vehicles by them. It was also marked that with increasing age of the respondents, level of satisfaction with urban environment came down. Older people, who had been exposed to better environment earlier, were relatively unhappy with its current state.
\end{abstract}

\section{Introduction}

The ever increasing population and its changing structure in most of the modern day cities has resulted in bringing drastic changes in the existing land use pattern in and around those cities, ultimately affecting the city environment. Ecologically, a city can be considered as a fabricated landscape of the biosphere, often referred to as a techno-ecosystem, which is highly energy intensive in nature. These pockets, in the absence of sustainable maintenance strategy of the urban environment, face problems related to environment pollution, housing, transport system, health infrastructure and other civic amenities and services. Though information about the existing problems of urban environment for proper environmental management can be obtained from a variety of sources, it is equally important to consult the public too, regarding their perception of the same. As discussed by Zhang et al. (2007), public attitudes have a significant influence on many aspects including the public budgetary process and subsequent fund allocation, public involvement and participation, and therefore it is important to consult the common men for better understanding their attitudes, which would be helpful in developing a diverse and adoptable strategy for sustainable city environment management. In the words of Poungsomlee and Ross (1992), ordinary people make links between environmental, human and societal influences on their habitats and behaviour in a way, which experts seldom can, because their own daily experience provides the points of integration. Normally people agree with the research and official studies as to which urban environmental problems are important; but analyze their causes and effects in a fresh, integrative and personalized way as they consider their economic and social circumstances to be inseparable from the

a Post Graduate Department of Population Studies, F. M. University, Balasore - 756020, Orissa, India

${ }^{b}$ Department of Migration and Urban Studies, International Institute for Population Sciences, Mumbai - 400088, India

nihar_rout@rediffmail.com, niharfmu@gmail.com environmental problems. White and Hunter (2005) have reported that the importance of broad public participation in decision-making with regard to sustainable development of environment is being recognized now. According to them, engaging the local voice within the agenda setting may improve policy makers' ability to respond to issues of most salience to local residents.

Al-Soliman (1990) in his study on urban environmental attributes found that the type of setting one lives in influences the perception of a common environment. Cultural background as well as various socio-economic characteristics, like occupation, education, age group, residence type, number of children etc. exerts some influence on the perception differential regarding a common environment. There have been many studies in the developed nations about human dimensions of environmental change (Curran et al., 2002) and increasing public concern with environmental issues in recent time (Mertig, Dunlap and Morison, 2002). However little is known about the socio-demographic correlates of the environmental perspectives expressed by individuals in developing settings (White and Hunter, 2005).

Apart from value orientation, which is supposed to be important to the formulation of environmental concern (Stern and Dietz, 1994), there are socio-economic correlates of such concerns too. For example, Adeola (2007) stressed on the possibility of minority migrant groups having lower levels of trust in the government and other entities. According to him immigrants are expected to exhibit less trust in the institutions and social organizations and high-risk perception relative to their native born counterparts. Similar analyzes were also made by Hunter (2000).

Bhubaneswar, the capital city of the state of Orissa, located in the eastern coast of India (shown in figure 1), is one of the fastest growing cities in the country. Owing to an increasing number of educational institutions and other organizations, and better employment opportunity, the city has always attracted migrants from all over the state. In fact, as per 2001 census figures (calculated using D03UC series data of 2001 Census, Government of India, on the profile of life time migrants in the cities of the state of Orissa in India) 63.57 percent of the total population were found to be migrants in the city of Bhubaneswar, which is currently hosting around one million population (Anon, 2011). Census results of various years (as cited in Rout, 2008) have clearly indicated that Bhubaneswar has been one of the fastest growing cities in India and has got doubled of its population during most of the inter-censal periods after independence. Demographically, the city does not have a favourable sex ratio for the females (796 females per 1000 males) and its overall literacy rate has sprung from a mere 64 percent to almost 88 percent during the postindependence period. As far as 2001 census results are concerned, the city, spread over an area of 134.64 sq. $\mathrm{km}$. has an overall population density of 4813 persons per sq. km. Regarding the occupational structure of the 
city, Bhubaneswar has never been considered as an industrial centre, with less than two percent of its workers being engaged as industrial workers and almost 96.52 percent of the workers are engaged in service sector and business (Rout, 2008). Massive growth of population along with changing structure of urban economy and infrastructure has resulted in a continuous change in the land use pattern of the city, over the years. In turn, land use change coupled with other factors like vehicular growth, and increasing use of material and energy has significantly affected the city environment and status of urban infrastructure in the city. This study is an attempt to explore the perception of city dwellers on different aspects of urban environment in the city of Bhubaneswar in India, and to draw a comparative picture regarding the perceived problems associated with the urban environment and infrastructure, among the city dwellers in different types of residential areas in the city. Further, the study aims at exploring the socio-economic correlates of the existing perception differentials regarding the state of city environment, among the urbanites.

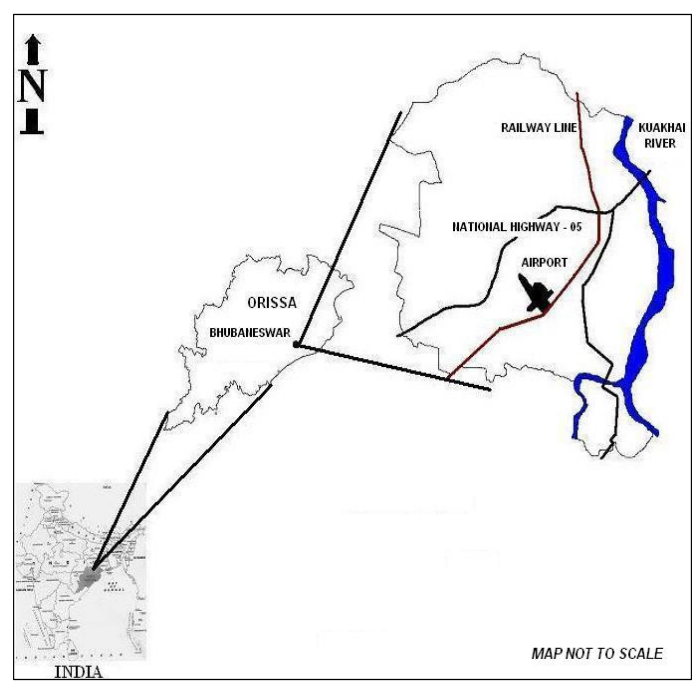

Figure 1

Location Map of the Study Area

\section{Methodology}

For finding out the perception of city dwellers about urban environment and infrastructure, a survey was carried out in six different residential pockets of the city, during October-November 2007, covering a sample of 180 households selected on the basis of stratified systematic sampling. In the process of obtaining the samples, with reference to the classification done by Orissa State Pollution Control Board (2003) the entire city was divided into six different categories, based on the availability of different infrastructure in those areas, namely-

- Residential area with good infrastructure

- Residential area with average infrastructure

- Residential areas with poor infrastructure

- Industrial area

- Slums in the main city area

- Slum in the outskirt

One residential pocket from each category of localities was selected randomly followed by the selection of 30 households from each of those pockets. The pockets selected for data collection process were: IRC Village (Good infrastructure), VSS Nagar (Average Infrastructure), Rasulgarh (Poor Infrastructure), Mancheswar (Industrial), Palasuni (Main city area slum) and Sikharchandi (Slum in the outskirt). Finally, the heads of the sample households were interviewed by using a structured interview schedule to obtain the required information. The respondents were asked to express their opinion regarding the problems observed in the city as a whole. However, as studies (e.g. AlSoliman, 1990) suggest that the types of setting of individuals' residences do influence their perception of a common environment; such responses might possibly be affected by their experiences of local level problems too. The interview schedule originally prepared in English was translated in to Oriya, the native language of the state and was used to carry out the face to face interview. The gathered raw data were entered, recoded as per requirement and analyzed by using SPSS 15 . The respondents, who did not respond to some particular set of questions, were excluded from the analysis, which made the ultimate sample size less than 180 for some of the parameters under study.

For the purpose of analysis, percentage distribution of the respondents was calculated with respect to: Level of different kinds of pollution, Level of various transportation problems and Satisfaction with the civic amenity services. Further, to obtain the summery measure of over all satisfaction with urban environment and services, three un-weighted indices, namely Physical Environment Quality Index (PEQI), Road Transport Quality Index (RTQI), and Civic Amenity Service Index (CASI) were computed for all the respondents.

For computing PEQI, information were collected on the four basic elements of the physical environment of the city, namely level of air pollution, level of water pollution, level of noise pollution, level of solid waste pollution and also on the level of mosquito prevalence, which was a major problem specific to the city of Bhubaneswar. Information were collected on a five point scale (Very Low, Low, Average, High and Very High) and considering the frequency distribution, three different values were assigned e.g. a value of ' 01 ' in case of 'Very low' and 'Low', '02' in case of 'Average' and '03' in case of 'High' and 'Very high' perceived levels. It was followed by an addition of all the five variables, and the computed index had a theoretical range of '05' to '15'. As the 'Average' response for all the variables resulted in an index value of 10 , any value above it was considered to be an indicator of perceived environmental quality of the city to be poor.

A similar approach was adopted for calculating RTQI, where information on the levels of six basic elements of road transportation was collected on the same five point scale. All the variables (Traffic problem, Road quality deterioration, Congestion, Accident, Lack of public transport system and Parking problem) considered for the computation of RTQI were negative in nature, and the values assigned to the responses were '01', '02'and '03',for 'Very Low or Low', 'Average', High or Very High' respectively. The computed RTQI, with a theoretical range of ' 06 ' to ' 18 ', was found to be having a value of 12 in case of all the responses be 'Average, and thus index value above 12 was considered to be showing dissatisfaction with road transport quality of the city.

The third index computed in the process was CASI for which, six different civic amenity services, namely Drinking water supply, Electricity supply, Garbage collection, Provision of streetlight, Quality of parks and Status of drainage system were considered. In fact, all the civic amenity services provided by the municipal corporation to different wards of the city were included for the study and the data were collected on a five point scale. First of all, a value of ' 1 ' was assigned to the responses 'Very Good' and 'Good', and a value of 
' 0 ' was assigned to the responses 'Average', 'Poor' and 'Very poor', which reflects whether the respondents were satisfied with these services or not? All these variables were simply added to compute CASI, which was having a theoretical range of ' 0 to 6 ', and it was considered that the city dwellers perceived the civic amenity services to be satisfactory only when the index value was more than three.

As a part of the reliability analysis, internal consistencies of the three indices were tested by using Cronbach's alpha statistic in SPSS 15 (shown in table 1). The computed values of both alpha and standardized alpha indicated that while CASI was in the level of excellence $(>.9)$, RTQI was found to be good (>.8) and PEQI was of the sample was illiterate, while almost equal number of respondents had high educational level. In this study migrants outnumbered the natives marginally. Almost 70 percent of the samples residents had their own house either legal or illegal as in the case of many slum dwellers.

Average household size being around five (Census 2001) in most part of the country, it was kept as a separate group. In fact, average urban household size has been computed to be 4.7 and 4.8 respectively for the state of Orissa and India as a whole (SRS 2004; Source: Mukherjee, 2011). However, households enumerated in the current study were marginally smaller (Mean $=4.69$ ), as most of the households were having

Table 1

Cronbach's Alpha for the Quality Indices

\begin{tabular}{|c|c|c|c|}
\hline SN & Psychometric Test Score (Number of Items) & Alpha & Standardized Alpha \\
\hline $\mathbf{0 1}$ & PEQI (5) & .7751 & .7732 \\
\hline $\mathbf{0 2}$ & RTQI (6) & .8279 & .8409 \\
\hline $\mathbf{0 3}$ & CASI (6) & .9291 & .9274 \\
\hline
\end{tabular}

found to be well acceptable (>>.7), as different composite indices.

Finally, the composite indices were cross tabulated against selected variables like type of locality, migration status, household size, ownership status, age group, educational level, and source of income for analyzing the correlates of existing perception differentials in the city regarding the urban environment and infrastructure.

\section{Results}

\section{Background Characteristics}

The background characteristics of the interviewed residents are shown in table 2 . The total sample size for the study was 180 , out of which around 26 percent were of age less than 35 years and the majority of the population were in between 35 years and 54 years of age. As far as educational level was concerned, the respondents were divided in to four categories: No Education (Illiterate), Low Education (Under Graduate), Moderate Education (Graduate) and High Education (Post Graduate). It was found that more than 31 percent household size of up to four members and almost half of the sampled households had one or two living rooms. As far as construction type was concerned, almost 69 percent of the households were pucca (concrete) in nature. In this study, characteristic features like having separate kitchen, separate bathroom, own toilet, using private tap as the main source of drinking water were reported by almost two third of the sampled households. It was found that around 64 percent of the households were using cooking gas as the major fuel and around 63 percent were purifying the drinking water in some way or the other.

\section{Environmental Problems}

As regard to various environmental problems (shown in Figure 2), air pollution was perceived to be a greater problem in comparison to other types of pollution in the city. While less than 16 percent perceived the air pollution level in the city to be low, as high as 43.5 percent had similar opinion about water pollution and noise pollution. Almost two third of the respondents considered that the level of solid waste pollution in the city was at high or very high

Table 2

Percentage distribution of respondents against selected background characteristics

\begin{tabular}{|c|c|c|c|c|c|}
\hline SN & Variable/ Category & Percentage & SN & Variable/ Category & Percentage \\
\hline \multirow[t]{5}{*}{01} & Age of the respondent & & 07 & Number of Living Rooms & \\
\hline & Less than 35 Years & 26.11 & & One & 33.33 \\
\hline & 35 to 44 Years & 44.44 & & Two & 16.11 \\
\hline & 45 to 54 Years & 18.33 & & Three & 27.78 \\
\hline & More than 54 Years & 11.11 & & Four or more & 22.78 \\
\hline \multirow[t]{5}{*}{02} & Educational Level & & 08 & Households with & \\
\hline & No Education & 31.67 & & Separate kitchen & 67.22 \\
\hline & Low education & 20.00 & & Separate Bathroom & 65.56 \\
\hline & Moderate education & 17.22 & & Own Toilet & 65.00 \\
\hline & High Education & 31.11 & & Water used after purification & 62.78 \\
\hline \multirow[t]{3}{*}{03} & Migration Status & & 09 & Drinking Water Source & \\
\hline & Migrant & 51.67 & & Private tap & 64.44 \\
\hline & Native & 48.33 & & Others & 35.56 \\
\hline \multirow[t]{3}{*}{04} & Ownership of House & & 10 & Major Fuel for cooking & \\
\hline & Own House & 69.44 & & LPG/ Cooking Gas & 63.89 \\
\hline & Rented House/ Quarter & 30.56 & & Kerosene/ Firewood & 36.11 \\
\hline \multirow[t]{4}{*}{05} & Household Size & & 11 & Source of Income & \\
\hline & Up to 04 & 52.22 & & Salary/Pension/Business & 57.78 \\
\hline & Five & 21.67 & & Daily wage & 42.22 \\
\hline & 06 or more & 26.11 & & & \\
\hline \multirow[t]{3}{*}{06} & Type of House & & & & \\
\hline & Pucca (Concrete) & 68.89 & & & \\
\hline & $\begin{array}{l}\text { Kuchcha } \text { (Thatched) \& Semipucca } \\
\text { (Semi concrete) }\end{array}$ & 31.11 & & & \\
\hline
\end{tabular}




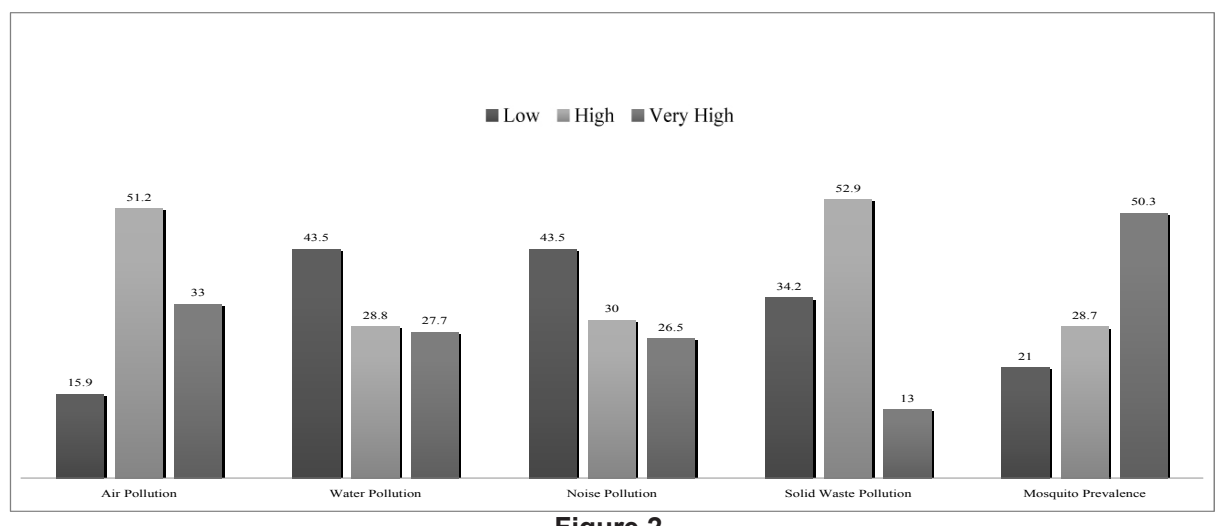

Figure 2

Bar Diagram showing Percentage of respondents against perceived categories of various environmental problems in the city

level. Though air pollution and solid waste pollution were being perceived as two major environmental concerns in Bhubaneswar, more than 56 percent of the respondents were also of the opinion that water quality and noise level were in a critical stage in the city. However, the biggest problem, which was considered to be a bigger one with respect to any one of the above-mentioned conditions, was mosquito prevalence. Respondents perceiving mosquito prevalence to be the major problem for the city constituted nearly 80 percent of the sample. Beside the five indicators used for this analysis, another crucial element was found to be water logging. In fact, the study revealed that as high as 56.5 percent of the respondents did perceive the problem of water logging in the city to be at a high or very high level.

\section{Transportation Problems}

Over dependence of personal vehicles for different activities has become a norm in many of the cities now. This particular tendency must have been able to reduce the requirement of public/ mass transport system in Bhubaneswar and that was the reason why around 47 percent of the respondents did not think lack of public transportation facility as a major problem in the city, despite of the fact that Bhubaneswar has never been a city with adequate or good mass transport system. Another positive finding noticed in the study was related to road quality of Bhubaneswar. As portrayed in Figure 3 , not many respondents perceived deteriorating road quality to be a big problem in the city, with only 6.5 percent of respondents reporting this to be a problem of a very high level. The biggest problem related to transportation system in the city was found to be parking and 75 percent of the respondent perceived parking problem in the city to be at very high level, seeking urgent attention by the planners. Growing problems of traffic jam, congestion and road accident were reported as the other major issues, which had been in a critical state as far as city dwellers' perception in Bhubaneswar was concerned.

\section{Civic Amenities}

Though it is expected that there would be variation in the provision of civic amenities in different parts of the city, an overall statistics, as represented in Table 3, suggest that number of people feeling satisfied with the services has been more than that, who are not satisfied. Among different civic amenities in the city, electricity supply was the one with which the city dwellers were mostly satisfied. While more than 82 percent of the respondents were satisfied with the electricity supply, only 64.4 percent of respondents felt satisfied with supply of drinking water in Bhubaneswar. 'Garbage collection', 'Streetlight provision and maintenance', and 'Quality of parks' were considered to be bigger problem with around 62 percent of the sample expressing their satisfaction with these services. However, the biggest problem of the city, as perceived by the residents was drainage system, with which as high as 45.6 percent of the respondents were not at all satisfied.

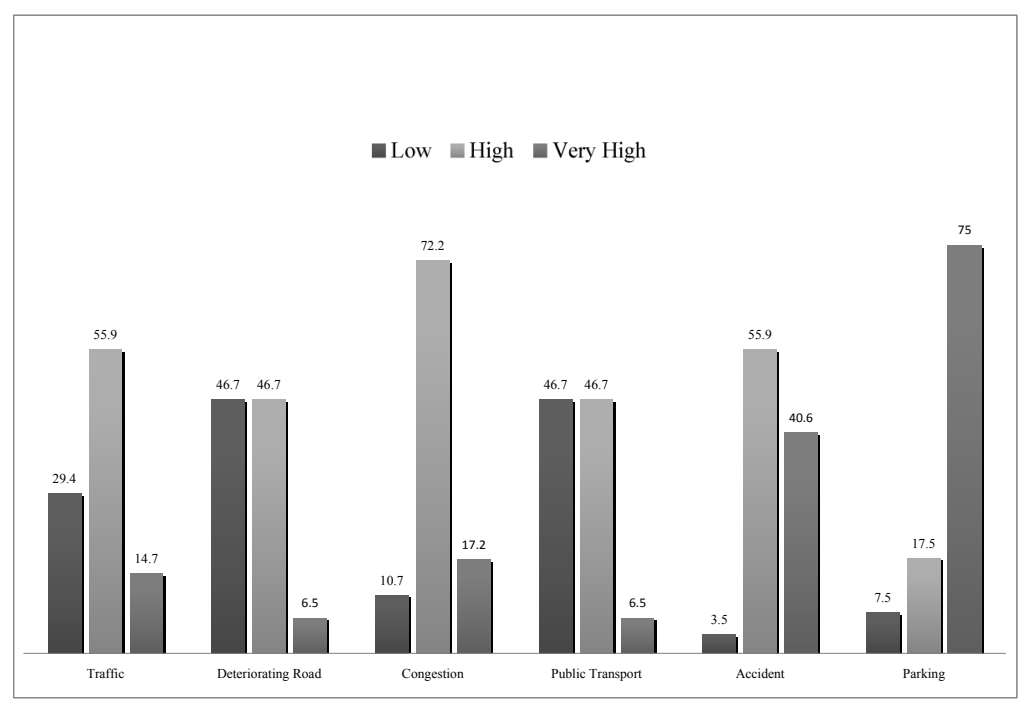

Figure 3

Bar Diagram showing Percentage of respondents against perceived categories of various transportation related problems in the city 
Table 3

Percentage distribution of respondents feeling satisfied with civic amenities in Bhubaneswar

\begin{tabular}{|c|l|c|c|}
\hline SN & Civic Amenity Services & Percentage & N \\
\hline 01 & Drinking Water Supply & 64.4 & 171 \\
02 & Electricity Supply & 82.4 & 171 \\
03 & Garbage Collection & 61.4 & 171 \\
04 & Street Light & 62.6 & 171 \\
05 & Park Quality & 61.4 & 171 \\
06 & Drainage System & 54.4 & 171 \\
\hline
\end{tabular}

Quality Index of City Infrastructure and Environment As mentioned in the methodology, the three un-weighted indices were having different theoretical range (05 to 15 in case of PEQI; 06 to 18 in case of RTQI and 0 to 06 in case of $\mathrm{CASI}$ ) and the respondents with values $<=10$, $<=12$ and $>3$ were considered to be satisfied with the quality of physical environment, road transportation and available civic amenity services of the city, respectively. After dividing the population in to the categories 'satisfied' and 'not satisfied', the recoded quality index variables were cross tabulated against different background variables and its summarized form has been presented in Table 4. It was found that 'type of locality', 'size of the household', and 'sources of income' were significantly associated with all the three indices, while 'educational level of the respondents' were significantly associated with two of those indices (except RTQI) and 'migration status' showed a significant association with PEQI.

\section{(a) Environmental Quality}

Though Bhubaneswar is not that much polluted as many other large cities of the country like Delhi, Mumbai, Kolkota and Ahmedabad, yet only 40 percent of the respondents felt Bhubaneswar to be a pleasant city to live in. Considering a number of environmental parameters in a single index, it was observed that there was hardly any individual in the slums, who was satisfied with the physical environment of the city. Another similar finding was that only 12.5 percent of the daily wageearning respondents were satisfied with the physical environment of the city, while the corresponding figure was more than 60 percent for the rest. Respondents from areas, which were supposed to be relatively poor as far as infrastructural availability was concerned, were also not very happy with the city environment. Just like many other studies, it was also noticed in this analysis that as high as high as 59.3 percent of the natives were satisfied with the environment compared to 22.5 percent in case of migrants. Considering the household size, it

Table 4

Percentage distribution of respondents satisfied with quality of different services and environment of the city against selected background variables

\begin{tabular}{|c|c|c|c|c|c|}
\hline $\mathbf{S N}$ & Variable/ Category & $\begin{array}{c}\text { Physical } \\
\text { Environment } \\
\text { Quality }\end{array}$ & $\begin{array}{c}\text { Road } \\
\text { Transport } \\
\text { Quality }\end{array}$ & $\begin{array}{c}\text { Civic } \\
\text { Amenity } \\
\text { Services }\end{array}$ & $\mathbf{N}$ \\
\hline $\mathbf{0 1}$ & $\begin{array}{l}\text { Type of Locality } \\
\text { Good Residential } \\
\text { Average residential } \\
\text { Poor Residential } \\
\text { Slum (Main City Area) } \\
\text { Slum (Outskirt) } \\
\text { Industrial }\end{array}$ & $\begin{array}{c}* * \\
84.0 \\
40.0 \\
34.6 \\
00.0 \\
03.0 \\
83.3\end{array}$ & $\begin{array}{c}* * \\
04.0 \\
43.3 \\
51.9 \\
06.9 \\
90.0 \\
07.1\end{array}$ & $\begin{array}{c}* * \\
100.0 \\
100.0 \\
92.6 \\
00.0 \\
00.0 \\
90.0\end{array}$ & $\begin{array}{l}30 \\
30 \\
30 \\
30 \\
30 \\
30\end{array}$ \\
\hline $\mathbf{0 2}$ & $\begin{array}{l}\text { Migration Status } \\
\text { Migrant } \\
\text { Native }\end{array}$ & $\begin{array}{c}* * \\
22.5 \\
59.3\end{array}$ & $\begin{array}{l}32.2 \\
37.8\end{array}$ & $\begin{array}{l}53.9 \\
72.0\end{array}$ & $\begin{array}{l}93 \\
87 \\
\end{array}$ \\
\hline $\mathbf{0 3}$ & $\begin{array}{l}\text { Size of the Household } \\
\text { Less than Five } \\
\text { Five } \\
\text { More than Five }\end{array}$ & $\begin{array}{c}* * \\
54.9 \\
13.5 \\
31.0\end{array}$ & $\begin{array}{c}* * \\
20.0 \\
61.1 \\
44.2 \\
\end{array}$ & $\begin{array}{c}* * \\
76.9 \\
52.6 \\
40.5 \\
\end{array}$ & $\begin{array}{l}94 \\
39 \\
47\end{array}$ \\
\hline 04 & $\begin{array}{l}\text { Ownership of the House } \\
\text { Rented House/ Quarter } \\
\text { Own House }\end{array}$ & $\begin{array}{l}39.6 \\
40.2\end{array}$ & $\begin{array}{l}33.3 \\
35.6\end{array}$ & $\begin{array}{l}79.2 \\
55.1\end{array}$ & $\begin{array}{c}55 \\
125\end{array}$ \\
\hline $\mathbf{0 5}$ & $\begin{array}{l}\text { Age Group } \\
\text { Less than } 35 \text { Years } \\
35 \text { to } 44 \text { Years } \\
45 \text { to } 54 \text { Years } \\
55 \text { Years or more }\end{array}$ & $\begin{array}{l}47.8 \\
40.3 \\
39.3 \\
21.1\end{array}$ & $\begin{array}{l}39.1 \\
39.5 \\
32.1 \\
10.5\end{array}$ & $\begin{array}{l}60.9 \\
64.1 \\
64.3 \\
57.9\end{array}$ & $\begin{array}{l}47 \\
80 \\
33 \\
20\end{array}$ \\
\hline 06 & $\begin{array}{l}\text { Educational Level } \\
\text { No Education } \\
\text { Low education } \\
\text { Moderate education } \\
\text { High Education }\end{array}$ & $\begin{array}{c}* * \\
01.8 \\
31.3 \\
60.0 \\
73.6\end{array}$ & $\begin{array}{l}49.1 \\
32.3 \\
30.0 \\
24.5\end{array}$ & $\begin{array}{c}* * \\
00.0 \\
72.7 \\
100.0 \\
100.0\end{array}$ & $\begin{array}{l}57 \\
36 \\
31 \\
56\end{array}$ \\
\hline 07 & $\begin{array}{l}\text { Source of Income } \\
\text { Salary/Pension/Business } \\
\text { Daily wage }\end{array}$ & $\begin{array}{c}* * \\
60.2 \\
12.5 \\
\end{array}$ & $\begin{array}{c}* * \\
24.7 \\
48.6\end{array}$ & $\begin{array}{c}* * \\
91.8 \\
23.3\end{array}$ & $\begin{array}{r}104 \\
76 \\
\end{array}$ \\
\hline & Total & 40.0 & 34.9 & 62.6 & 180 \\
\hline
\end{tabular}

$* *: p<=.001$ 
was observed that respondents from smaller households reported higher level of satisfaction with the city environment. It was found that with increasing age of the respondents, level of satisfaction came down. Almost 48 percent of the respondents with age less than 35 years were satisfied with the city environment, compared to 21 percent in case of those with age 55 years or more suggesting that older people, who had been exposed to better environment earlier, were relatively unhappy with the current state. Similarly about 2 percent of the respondents with no education, who were supposed to be staying mostly in the slums, were satisfied with the environment quality while the corresponding figure was as high as 73.6 percent in case of those with high level of education.

\section{(b) Road Transport Quality}

As far as road transport quality index was concerned, Bhubaneswar has been found to be in a precarious situation with less than 35 percent of the sample showing their satisfaction with the facilities. Unlike other urban areas of Orissa, in fact road quality had never been considered as a big problem in Bhubaneswar. However problem of parking facility and congestion were expected to affect the city dwellers' perception about road transport negatively. Surprisingly, 90 percent of the respondents of slum areas were satisfied with the road transport quality of Bhubaneswar and that might be because of their location in a less crowed area without much traffic and congestion. However, affluent residents of the good residential area were least satisfied with the service. Absence of parking areas for their cars and time loss in the traffic might be the reasons behind such a response. Slum dwellers of the main city area and residents of the industrial area were also not at all happy with the road transportation clearly pointing towards the absence of proper maintenance of roads approaching those places. Lower level of satisfaction was also marked in case of small household respondents, respondents with age 55 or above and those earning their income through regular service or business. The satisfaction level was also found to be decreasing with increasing education. While 49.1 percent of respondents with no education were satisfied with the road transport quality, only 24.5 percent of those with high level of education were of similar perception in Bhubaneswar.

\section{(c) Civic Amenity Services}

Overall, the status of civic amenities in the city could be put in the bracket of above average with more than 62 percent of the respondents showing their satisfaction for the same. However, the cross tabulation clearly suggested that there had been a wide disparity in service provision between slum and non-slum households. While all the residents from good or average residential areas were highly satisfied with the civic facilities of the city, not a single respondent was of similar opinion in the slums. Similar observations were also made with respect to educational level and income source. Daily wage earners, who were supposed to be staying mostly in the slums, were far less satisfied with the services in comparison to the rest of the respondents. The satisfaction trend also showed a clear rise with increase in educational level. In fact the percentage was zero for those with no education, and 100 per cent for those with either moderate or high educational level. All these findings clearly ask for an immediate response towards providing necessary services to the slums areas and improving the quality of existing services.

\section{Discussion}

Enormous growth in population in the city of Bhubaneswar has been found to be the biggest culprit behind most of the problems reported by the urbanites. In fact, the city, which was originally planned for a population of 40,000 (OSPCB, 2003), was found to be accommodating more than one million people in 2007 , of which 0.82 million people were located inside the municipal corporation area (BDA, 2007). Most of the problems in the city can be attributed to the lopsided development in the urban infrastructure unmatched with the city population growth. Air pollution, which was considered to be one of the major environmental problems of the city, was in fact a result of rising vehicular emission. Growing vehicular population had also resulted in problems of parking, accident, congestion and traffic, which was clearly evident from the study. Interestingly, the respondents did not think lack of public transportation facility as a major problem, which could be attributed to the increasing tendency of using personal vehicles by the city dwellers. However, such behaviour could trigger the risk of even more air pollution in the city. It was obvious that the residents of the slum located in the outskirt were experiencing better space availability, less traffic and less congestion, as a result of which, were quite satisfied with the road transport quality of the city. Daily wage earners, who were not much affected by traffic, congestion and parking were found to be more satisfied with the service. Two more problems, which were perceived to be in a critical stage, were mosquito prevalence and absence of proper drainage system in the city. Individual household members depending on their age, sex and relationships, may hold very different perceptions of the environment (Izazola, Martinez and Marquette, 1998). This study also revealed that older respondents, migrants and slum dwellers, who happen to be less educated too, were less satisfied with the overall city environment. Regarding the variation in perception about the physical environment, slum dwellers, quite obviously due to their unhygienic surroundings, reported about an extremely poor quality of environment in the city. On the other hand, natives, smaller household occupants, better educated and better employed respondents, who were possibly staying in better localities were more satisfied with the quality of physical environment. It was interesting to note that most of the people residing in the non-slum localities were satisfied with the available civic amenities, whereas not a single respondent in either of the slums was satisfied with the services available. Majumder et al. (2007) had found a statistically significant association between income and level of satisfaction with the city environment, where low-income-group had the lowest value of satisfaction index in Chittagong (Bangladesh). Similar observations were also made in the current study. Slums, which mostly accommodate people of relatively lower economic strata, were the places, where dissatisfaction with urban environment and services was strongly felt. It talks about the existing disparity in service provision between slum and non-slum households that seeks a straight away attention of the urban authority for a timely solution of the problem.

\section{Conclusion}

There is no doubt that for achieving good quality of human life, city development must match with the growth of city population and its requirement. Therefore, availability of infrastructure is a very important issue and equally important is the perception of city dwellers regarding the process of developmental activities, as perception decides the level of use of available amenities and reflects the level of satisfaction too. In fact, according to Brown (2003) community members are the experts on the environmental problems they face, and most cases of widespread environmental contamination are initially revealed by them. A few important issues of concern came out of this analysis, in which the city of 
Bhubaneswar seemed to be at a critical stage as far as the perception of dwellers was concerned. Notable among those problems are lack of safe and sufficient water supply, presence of pollutants in the environment, high prevalence of mosquito in the city, unavailability of basic infrastructure such as sewerage and drainages system, effective collection and disposal of urban wastes, lack of parking and public transport facilities and provision of street light. Such deterioration of the urban environment, along with overcrowded living conditions increases the health risk of city dwellers and may lead to a collapse of the entire city structure. Another problem has been the growing disparity in providing required services to the entire population located in different parts of the city. Although these services, infrastructure and state of environment are seen to be at a satisfactory level for some groups of the population, the situation has been pathetic for many others, especially for the slums dwellers. Therefore, with the expansion of urban area and its population, there is a need to increase the infrastructural facilities in terms of transport and communication, water supply and sanitation, and above all medical facilities so that it could cope with the increasing requirement of the city population. Necessary steps are to be taken to facilitate the requirements of the city dwellers, keeping the entire system in a sound and sustainable environmental framework. Immediate actions must be taken to sort out the problems in priority areas for reducing the disparity, followed by a concerted planned effort to maintain and deliver the services as required by the city dwellers. Bhubaneswar is one of the few selected cities of India, which are under the currently functioning Jawaharlal Nehru National Urban Renewal Mission (JNNURM) of the country. Beside, with the help of other urban bodies and national level organizations, there has been an active attempt by both Bhubaneswar Development Authority (BDA) and Bhubaneswar Municipal Corporation (BMC) to prepare and implement an effective city development plan. Though looking at the volume and heterogeneity of the city population, findings from a small sample of 180 respondents may not be considered as a generalized view of the urbanites, such a study would definitely be able to provide valuable inputs for proper planning of the city.

\section{References}

Adeola, F. O. (2007). Nativity and environmental risk perception: an empirical study of native-born and foreign-born residents of the USA. Human Ecology Review, 14(1), 13-25.

Al-Soliman, T. M. (1990). The impact of the surrounding environment on people's perception of major urban environmental attributes. Architecture and Planning: Journal of King Saudi University, 2, 43-60.

Anon (2011). India Population 2011. Retrieved from http://exploredia.com/india-population- 2011/\# more-5629 (Date of access: May 19, 2011).

BDA (2007). Population growth in Bhubaneswar Development Authority. Retrieved from http:// www.bdabbsr.in/bdaservlets/bhubaneswar.do (Date of access: March 30, 2010).

Brown, P. (2003). Qualitative methods in environmental health research. Environmental Health Perspectives, 111, 1789-1798.

Census (2001). Data Highlights - HH - I: Normal households by household size. Retrieved rom www.censusindia.gov.
in/Data.../Data.../data_highlights_hh1_2_3. pdf (Date of access: May 19, 2011)

Curran, S., Kumar, A., Lutz, W., \& Williams, M. (2002). Interactions between coastal and marine ecosystems and human population systems: Perspectives on how consumption mediates this interaction.Ambio, 31, 264-268.

Hunter, L. M. (2000). A comparison of the environmental attitudes, concern, and behaviors of native - born and foreign-born U.S. residents. Population and Environment, 21(6), 565-580.

Izazola, H., Martínez, C. \& Marquette, C. (1998). Environmental perceptions, social class and demographic change in Mexico City: a comparative approach. Environment and Urbanization, 10(1), 107-118.

Majumder, A. K., Hossain, M. E., Islam, M. D. \& Sarwar, M. I. (2007). Urban Environmental Quality Mapping: A Perception Study on Chittagong Metropolitan City. Kathmandu University Journal of Science, Engineering and Technology, 1(4), 1-14.

Mertig, A. G., Dunlap, R. E., \& Morrison, D. E. (2002) The environmental movement in the United States. In R. E. Dunlap \& W. Michelson(Eds.), Handbook of Environmental Sociology (pp. 448 - 481). Westport, CT: Greenwood Press.

Mukherjee, P. (2011). Levels, Patterns and Determinants of Food Insecurity in Urban India. Retrieved from www.siteresources. worldbank. org INTURBANDEVELOPMENT/.../Mukherjee. pdf (Date of access: May 19, 2011)

OSPCB (2003). Environmental management plan of Bhubaneswar. Bhubaneswar: Orissa State Pollution Control Board.

Poungsomlee, A. \& Ross, H. (1992). Impact of modernisation \& urbanisation in Bangkok: An integrative ecological and biological study. Thailand: Institute for Population and Socia Research, Mahidol University.

Rout, N. R. (2008). Linkages between Population, Land Use and Environment: A Case Study of Bhubaneswar City. Unpublished Ph. D thesis, Mumbai: International Institute for Population Sciences.

Stern, P. C., \& Dietz, T. (1994). The value basis of environmental concern. Journal of Social Issues, 50, 65-84.

White, M. J., \& Hunter, L. M. (2005). Public perception of environmental issues in a developing setting, Research program on environment and behavior, Working Paper No. EB2005-0003. Boulder: University of Colorado.

Zhang, Y., Hussain, A., Deng, J., \& Letson, N. (2007). Public attitude towards urban trees and supporting urban tree programs. Environment and Behaviour, 39(6), 797-814. 